\title{
Roth Net-Assisted Endoscopic-Guided Manometry Catheter Placement
}

Dhineshreddy Gurala ${ }^{1}$, Jobin Philipose ${ }^{2}$, Abhishek D. Polavarapu ${ }^{2}$, Youssef El Douaihy ${ }^{2}$, Stephen M. Mulrooney ${ }^{3}$

1. Internal Medicine, Staten Island University Hospital - Northwell Health, New York, USA 2. Gastroenterology and Hepatology, Staten Island University Hospital - Northwell Health, New York, USA 3. Gastroenterology, Staten Island University Hospital - Northwell Health, New York, USA

Corresponding author: Dhineshreddy Gurala, dineshgurala@gmail.com

\begin{abstract}
High-resolution esophageal manometry (HRM) has become the gold standard to diagnose esophageal motility disorders. Usually, this procedure is performed by introducing the catheter, which has pressure sensors, into the esophagus and proximal stomach via the nares. Repeated coiling of the catheter and inability to pass through the gastroesophageal junction (GEJ) are common challenges encountered. Endoscopy-guided placement of the catheter can overcome these difficulties. However, sometimes even with the use of endoscopy, it is difficult to advance catheter due to anatomical variants. The extreme fragility of the catheter and sensors and the high cost of this reusable device precludes the use of biopsy forceps or snare to advance the catheter. There is no literature on using accessories during endoscopy in case of difficult placement under direct visualization. We report a unique case of using Roth Net via the suction channel to advance esophageal manometry catheter into the stomach by using endoscopy.
\end{abstract}

Categories: Internal Medicine, Gastroenterology

Keywords: manometry, roth net, endoscopy, dysphagia, achalasia, motility

\section{Introduction}

Esophageal manometry has been the method of choice for evaluation of esophageal motility disorders and also useful in the evaluation of gastroesophageal reflux disease (GERD) or non-cardiac chest pain [1]. Conventional esophageal manometry has been state of the art till the 1990s. The invention of highresolution esophageal manometry (HRM) in 1990 led esophageal evaluation to a new horizon. HRM combined with esophageal pressure topography (EPT) significantly increased the quality of pressure sensing and analysis of data as a topographic plot on the monitor. Usually, this procedure is performed by introducing the catheter and advance through the esophagus into the stomach via the nares in an awake patient. After achieving successful cannulation of the catheter, the patient is asked to take 10 swallows of 5 cc water followed by measurement of pressures and analysis of data. Any changes in consistency and quantity of swallows can affect manometry results [2,3]. In prior studies, $21 \%$ of HRM studies were technically imperfect, and $29 \%$ of those were due to the inability to traverse through lower esophageal sphincter (LES) and $12 \%$ due to failure to complete a minimum number of swallows [1]. These difficulties were circumvented by endoscopy-guided placement of manometry catheter. However, even with endoscopy due to repeated coiling of the catheter or due to anatomical variants, cannulation is difficult and prone to damaging the catheter/sensors, which precludes the use of accessories to smoothen the process and to prevent damage to the catheter. Herein we report a unique case of difficult placement of manometry catheter under endoscopy guidance, which was completed successfully by using Roth Net.

\section{Case Presentation}

A 59-year-old female with a history of acid reflux and diabetes, presented with dysphagia to solids and liquids for the last six months with progressive inability to swallow any food associated with weight loss of 6 pounds and loss of appetite. She denied any abdominal pain, nausea, vomiting, hematemesis, melena, hematochezia, or a family history of gastrointestinal malignancy. Vital signs at the time of admission were normal. Physical examination was negative for any abdominal distension or tenderness. Initial esophagogastroduodenoscopy (EGD) showed esophageal dilatation without any intraluminal mass, as shown in Figure 1A. Barium esophagogram showed mildly dilated esophagus and little to no peristaltic activity (Figure $1 B$ ). Due to the inability to advance the manometry catheter without sedation, she was scheduled for endoscopic-guided placement. During EGD, at gastroesophageal junction (GEJ), some resistance was met but without any luminal abnormality in the mucosa. After completion of EGD, the manometry probe was introduced via the nares and advanced under endoscopic guidance, but the catheter repeatedly coiled in the oropharynx (Figure $1 \mathrm{C}$ ) and mid esophagus. The catheter was advanced and withdrawn to relive coiling, but still, the tip of the catheter couldn't be advanced beyond the GEJ. A Roth Net was introduced through the suction channel of the endoscope. The motility catheter tip was gently captured with the Roth Net (Figure 1D) and guided through LES and advanced into the antrum of the stomach (Figure 1E). 


\section{Cureus}

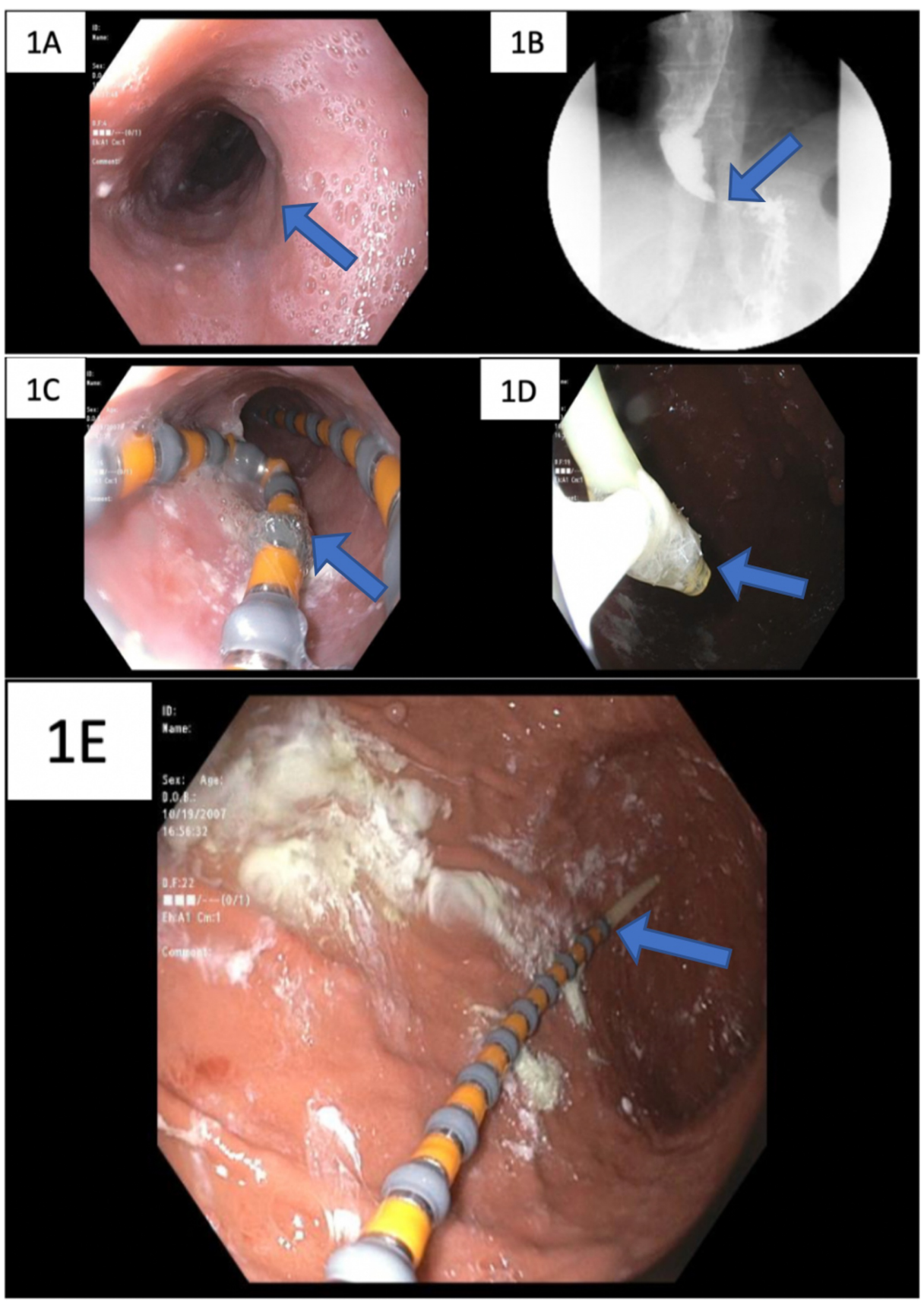

FIGURE 1: (A) Esophagogastroduodenoscopy (EGD) showing esophageal dilatation. (B) Barium esophagogram showing dilated esophagus with distal spasm (blue arrow). (C) Coiling of manometry catheter in the esophagus. (D) Tip of the manometry catheter was captured by the Roth Net. (E) Successful placement of the catheter in the antrum of the stomach.

The endoscope was removed. One hour later, manometry was performed, showing findings consistent with type II achalasia (Figures 2-4). 


\section{Cureus}

High Resolution Impedance Manometry Report

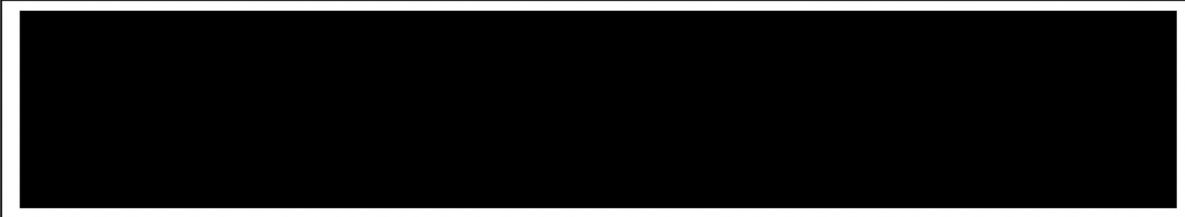

\section{Patient History}

Symptoms / Indications

Endoscopic Findings

Medications

Notes

\section{Other Findings}

IRP is elevated. Peristalsis is absent. Distil latency decreased with premature contractions.. Multiplle secondary isobaric contractions are present. Borderline PEP in liquid, multiple PEP in viscous

\section{Findings}

LES

LESP (mid resp.)

Total Length

Median IRP

EGJ Morphology

Lower Esophageal Body (Liquid: 12 swallows)

$\frac{\text { Chicago Classification Metrics }}{\text { Normal DCI }(450-8000)}$

Mean DCl

Hypercontractile $(\mathrm{DCl}>8000)$

Premature $(\mathrm{DL}<4.5)$

Panesophageal

Panesophageal

Conventional Metrics

\section{DEA}

Peristaltic

Ineffective

Simultaneous

Retrograde

Non-Transmitted

$\begin{array}{ll}33 \mathrm{mmHg} & \frac{\text { Normal }}{10-45} \\ 4.1 \mathrm{~cm} & <=20 \\ \frac{27 \mathrm{mmHg}}{T y p e ~} & \end{array}$

$\frac{\text { Normal }}{10-45}$

$<=20$

Type I

$>=50.0$

$0.0 \%$

$>=50.0$

$95 \mathrm{mmHg} \cdot \mathrm{s} \cdot \mathrm{cm}$
$100.0 \%$

$\frac{100.0 \%}{0.0 \%}<20.0$

$50.0 \%$

Achalasia Type III -

* Ineffective includes weak, failed, and fragmented swallows.

** Pattern Classification does not constitute a diagnosis. It may be invalid if the patient has had prior related surgeries. Impedance
Distal Baseline Impedance
Complete Transit (Viscous: 13 swallows)
261 ohms
$0.0 \%$
$>=80.0$

$\begin{array}{ll}35 \mathrm{mmHg} & <=220 \\ 16.7 \% & >=80.0\end{array}$

$\frac{16.7 \%}{25.0 \%} \quad<50.0$

$41.7 \%$

$0.0 \% \quad<20.0$

\section{Impressions}

Type II Achalasia

Diagnosis

Type II Achalasia.

\section{FIGURE 2: Manometry report.}

IRP: Integrated relaxation pressure; LES: Lower esophageal sphincter; IRP: Integrated relaxation pressure; EGJ: Esophagogastric junction; DCI: Distal contractile integral. 


\section{Cureus}

\section{Resting}

LES

$\begin{array}{ll}\text { Proximal } & 39.2 \mathrm{~cm} \\ \text { Distal } & 43.3 \mathrm{~cm} \\ \text { Total Length } & 4.1 \mathrm{~cm} \\ \text { PIP } & 39.2 \mathrm{~cm} \\ \text { Intra-abdominal Length } & 4.1 \mathrm{~cm} \\ \text { EGJ Relative to LES } & 0.6 \mathrm{~cm} \\ \text { EGJ Morphology } & \text { Type I } \\ & \\ \text { LESP (mid resp.) } & 33 \mathrm{mmH}\end{array}$

Normal

$\mathrm{cm}$

$\mathrm{cm}$

$2 \mathrm{~cm}$

$6 \mathrm{~cm}$

$33 \mathrm{mmHg}$

$10-45$

* If LESP is measured in more than one measurement, then the average value is reported.

Esophageal Body

Impedance

Distal Baseline Impedance

UES

$\begin{array}{ll}\text { Proximal } & 16.1 \mathrm{~cm} \\ \text { Distal } & 18.1 \mathrm{~cm} \\ \text { Total Length } & 2.0 \mathrm{~cm} \\ & 25 \mathrm{~m}\end{array}$

$21.1 \mathrm{~cm}$

261 ohms

$6.1 \mathrm{~cm}$

$\underline{25 \mathrm{mmHg}}$
Normal

$30-118$

* If UESP is measured in more than one measurement, then the average value is reported.

\section{Liquid Swallow Chicago Classifications}

LES/Lower Esophageal Body (12 swallows)

\begin{tabular}{ll} 
Swallows & $\begin{array}{c}\text { IR } \\
\text { m }\end{array}$ \\
\hline 1 & $\underline{25}$ \\
\hline 2 & $\underline{30}$ \\
3 & $\underline{34}$ \\
4 & $\underline{31}$ \\
5 & $\underline{35}$ \\
6 & $\underline{27}$ \\
7 & $\underline{27}$ \\
8 & $\underline{26}$ \\
9 & $\underline{27}$ \\
10 & $\underline{28}$ \\
11 & $\underline{24}$ \\
12 & $\underline{29}$ \\
&
\end{tabular}

Median IRP

Mean DCl

$\begin{aligned} & \text { IRP } \\ & \mathbf{m m H g} \\ & <=20\end{aligned}$
$\frac{\underline{25}}{\frac{30}{34}}$
$\frac{\underline{31}}{35}$
$\frac{\underline{27}}{\underline{27}}$
$\underline{\underline{26}}$
$\underline{\underline{27}}$
$\underline{\underline{24}}$

DL

DCI

$\mathrm{mmHg} \cdot \mathrm{s} \cdot \mathrm{cm}$
$450-8000$

$>=4.5 \quad 450$

$\frac{\frac{16}{11}}{\frac{57}{107}}$

$\frac{\frac{1.0}{1.2}}{\frac{1.1}{1.6}} \quad \frac{\frac{17}{107}}{\frac{149}{119}}$

$\frac{57}{107}$

$\frac{149}{119}=$

$\frac{119}{\frac{49}{214}}$

$\frac{214}{149}$

$\underline{1.1} \underline{75}$

PB

$\underset{<=5.0}{\mathrm{~cm}}$

$\mathrm{CV}^{*} \mathrm{CP}^{\star \star} \quad$ IBPP**

$<=20$

$\frac{27 \mathrm{mmHg}}{95 \mathrm{mmHg} \cdot \mathrm{s} \cdot \mathrm{cm}}$

EG $\quad 0.0 \%$

PA $\quad 0.0 \%$

Normal

${ }^{*} \mathrm{CV}$ (Contractile Vigor) = NO (Normal), WE (Weak), FA (Failed), HY (Hypercontractile)

(IN (Intact), PR (Premature), FR (Fragmented)

***IBPP (Intrabolus Pressure Pattern) = CO (Compartmentalized), EG (EGJ Pressurization), PA (Panesophageal)

FIGURE 3: Manometry report. 


\section{Cureus}

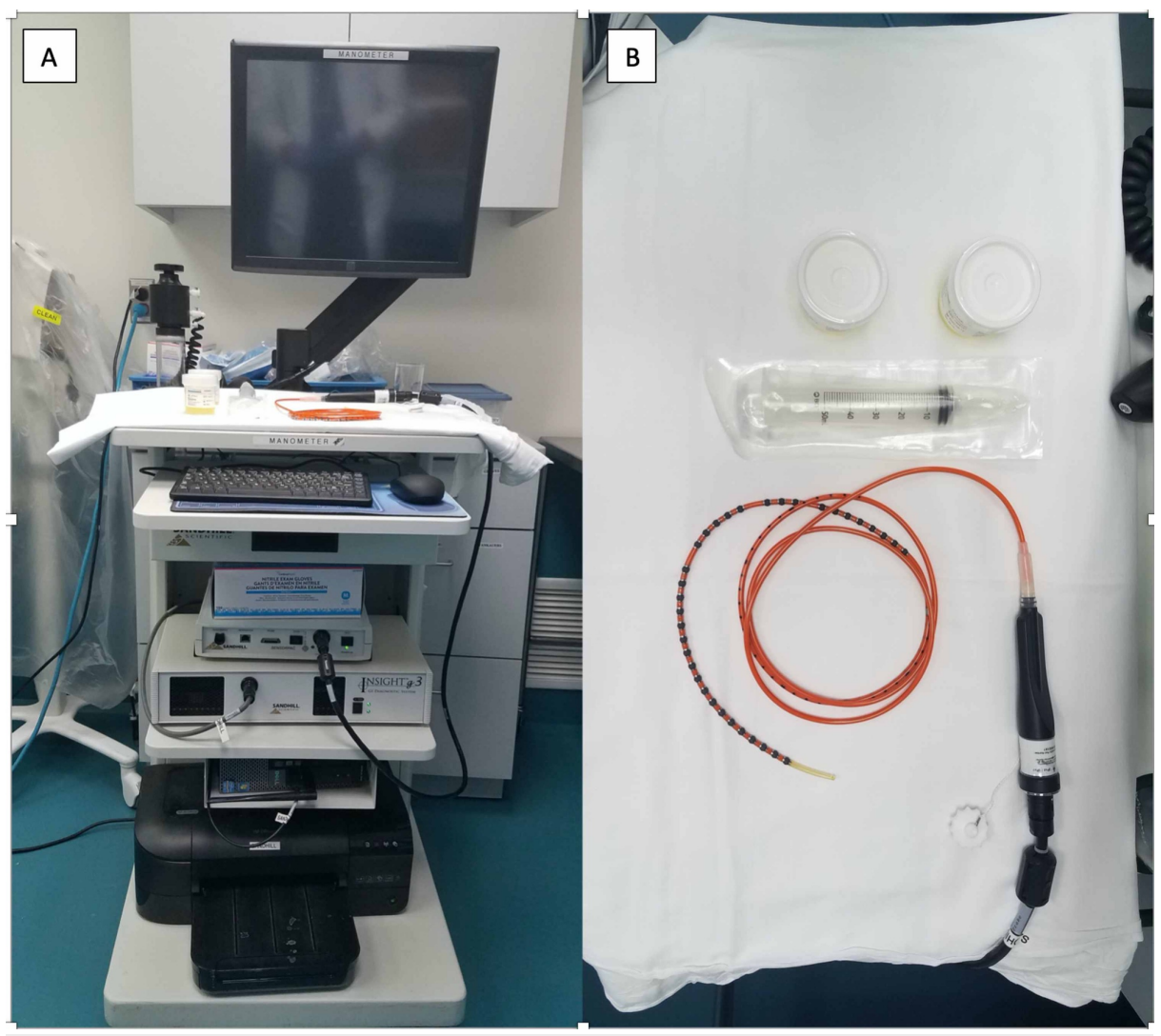

FIGURE 5: High resolution manometry set up (A) with manometry catheter (B). 


\section{Cureus}

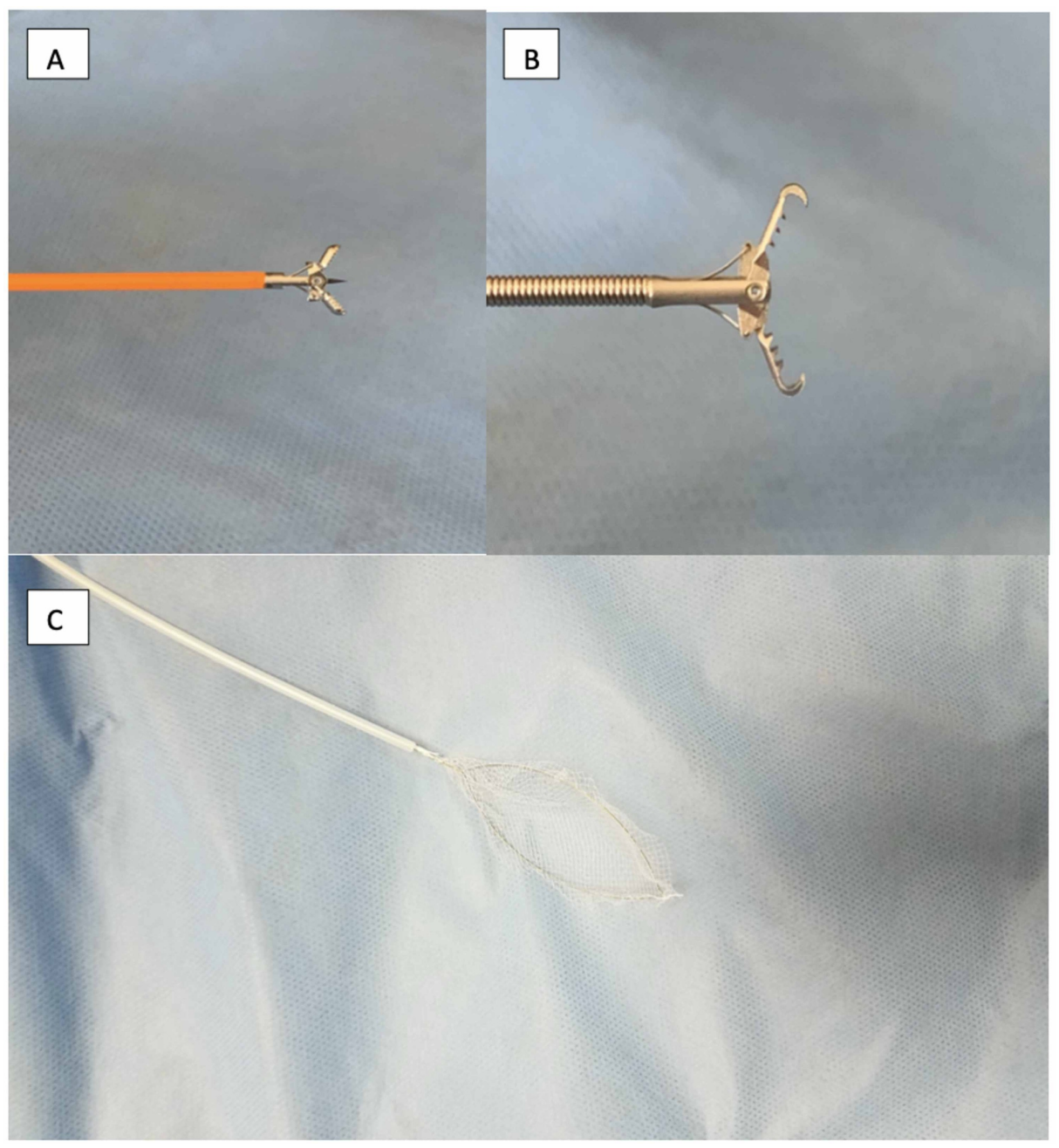

\section{FIGURE 6: Biopsy forceps (A), rat tooth forceps (B) displaying sharp interdigitated teeth could be a potential damage to the manometry catheter. (C) Roth Net.}

\section{Discussion}

Esophageal manometry to assess esophageal motility patterns is the standard test to diagnose esophageal motility disorders. Indications for performing the test include non-obstructive dysphagia, peristaltic reserve prior to anti-reflux surgery, symptoms of regurgitation, and non-cardiac chest pain [4]. The first conventional manometry system was developed by Wyle Jerry Dodds and Ron Arndorfer in 1970 [5], which has been state of the art for two decades till 1990. In 1990 Ray Clouse and his colleagues invented the HRM, which had revolutionized the clinical evaluation of esophageal motility disorders. Differences between conventional manometry and HRM are mentioned in Table 1. HRM evaluates the dynamic action of the upper esophageal sphincter, esophageal peristaltic patterns, and functional anatomy of GEJ. This data can be converted into seamless and dynamic spatiotemporal EPT or "Clouse plots" by advanced software algorithms. Measurements obtained from EPT plots like integrated relaxation pressure (IRP), distal contractile integral (DCI), distal latency (DL), and the contractile front velocity (CFV) can be used to classify esophageal motility disorder based on Chicago Classification (CC). 


\section{Cureus}

\section{Conventional manometry}

Cheap and durable

Typically, 3-5 sensors wide apart [5]

Low fidelity [5]

Takes more time than HRM average time of $\mathbf{2 4 . 4}$ minutes $[6,7]$

Need to reposition the catheter (pull through technique)[6]

Uses water perfused catheters which are stiffer and more uncomfortable

Unidirectional conventional line plot on the monitor [8,9]

Wave forms only [5]
High resolution manometry

\section{Expensive}

Closely placed pressure sensors up to 36 in number $1 \mathrm{~cm}$ apart[5]

High fidelity [5]

Quick and easy placement of catheter average time of 8.2 minutes $[6,7]$

No need for repositioning [6]

Uses solid catheters which are softer and more comfortable

Seamless and dynamic spatiotemporal EPT plots by advanced software algorithms $[8,9]$

Color contour [5]

TABLE 1: Differences between conventional manometry and HRM

HRM: High-resolution esophageal manometry; EPT: Esophageal pressure topography.

HRM with EPT is a new technique that facilitates more accurate measurement of pressure changes in the esophagus by using a specialized catheter with very closely placed pressure censors $1 \mathrm{~cm}$ apart along the length of the catheter. The patient is asked to fast for at least 6 hours before the procedure and avoid medications that can alter esophageal motility on the day of the examination like calcium channel blockers, nitrates, prokinetics, loperamide, beta-receptor antagonists, opiates, and anticholinergics [10]. During the procedure, a manometry catheter is introduced trans-nasally and advanced into the esophagus and stomach in an awake patient, and the distal sensor is advanced $2-3 \mathrm{~cm}$ below the diaphragm and the LES is visualized in the Clouse view 2-3 cm below the diaphragm [11]. This procedure is usually performed without sedation, but several anatomical factors such as the deviated septum, prior craniofacial surgeries, esophageal tortuosity, and tight LES make it difficult. Endoscopy-assisted placement of the catheter can overcome these obstacles and facilitate safe placement, regrettably, endoscopic manipulation of the catheter can also damage the catheter and its sensors, rendering it unusable. The cost of the catheter approaches $\$ 19000$, and once damaged, it cannot be repaired. Using a Roth Net inserted via the suction channel is a safe alternative in such situations to assist in the successful placement of the catheter, as in our case.

\section{Conclusions}

In conclusion, using endoscopic accessories such as a Roth Net can be helpful for the successful placement of endoscopic-guided manometry catheter placement in cases where the procedure would otherwise be impossible without risking damage to the manometry catheter. We propose the use of Roth Net for safe and effective placement of the catheter, which can reduce the procedure time, necessary anesthesia, and related complications.

\section{Additional Information}

\section{Disclosures}

Human subjects: Consent was obtained by all participants in this study. NA issued approval NA. NA. Conflicts of interest: In compliance with the ICMJE uniform disclosure form, all authors declare the following: Payment/services info: All authors have declared that no financial support was received from any organization for the submitted work. Financial relationships: All authors have declared that they have no financial relationships at present or within the previous three years with any organizations that might have an interest in the submitted work. Other relationships: All authors have declared that there are no other relationships or activities that could appear to have influenced the submitted work.

\section{References}

1. Christian KE, Morris JD, Xie G: Endoscopy- and monitored anesthesia care-assisted high-resolution impedance manometry improves clinical management. Case Rep Gastrointest Med. 2018, 2018:9720243. $10.1155 / 2018 / 9720243$

2. Xiao Y, Nicodème F, Kahrilas PJ, Roman S, Lin Z, Pandolfino JE: Optimizing the swallow protocol of clinical high-resolution esophageal manometry studies. Neurogastroenterol Motil. 2012, 24:489-496. 10.1111/j.1365-2982.2012.01989.x 


\section{Cureus}

3. Allen ML, Orr WC, Mellow MH, Robinson MG: Water swallows versus food ingestion as manometric tests for esophageal dysfunction. Gastroenterology. 1988, 95:831-833. 10.1016/s0016-5085(88)80036-2

4. Gyawali CP, Patel A: Esophageal motor function: technical aspects of manometry . Gastrointest Endosc Clin N Am. 2014, 24:527-543. 10.1016/j.giec.2014.06.003

5. Conklin JL: Evaluation of esophageal motor function with high-resolution manometry . J Neurogastroentero Motil. 2013, 19:281-294. 10.5056/jnm.2013.19.3.281

6. Roman S, Kahrilas PJ: Challenges in the swallowing mechanism: nonobstructive dysphagia in the era of high-resolution manometry and impedance. Gastroenterol Clin North Am. 2011, 40:823-835. 10.1016/j.gtc.2011.09.006

7. Fox MR, Bredenoord AJ: Oesophageal high-resolution manometry: moving from research into clinical practice. Gut. 2008, 57:405-423. 10.1136/gut.2007.127993

8. Gyawali CP, Bredenoord AJ, Conklin JL, et al.: Evaluation of esophageal motor function in clinical practice . Neurogastroenterol Motil. 2013, 25:99-133. 10.1111/nmo.12071

9. Clouse RE, Prakash C: Topographic esophageal manometry: an emerging clinical and investigative approach. Dig Dis. 2000, 18:64-74. 10.1159/000016967

10. Murray JA, Clouse RE, Conklin JL: Components of the standard oesophageal manometry . Neurogastroenterol Motil. 2003, 15:591-606. 10.1046/j.1365-2982.2003.00446.x

11. Yadlapati R: High-resolution esophageal manometry: interpretation in clinical practice. Curr Opin Gastroenterol. 2017, 33:301-309. 10.1097/MOG.0000000000000369 